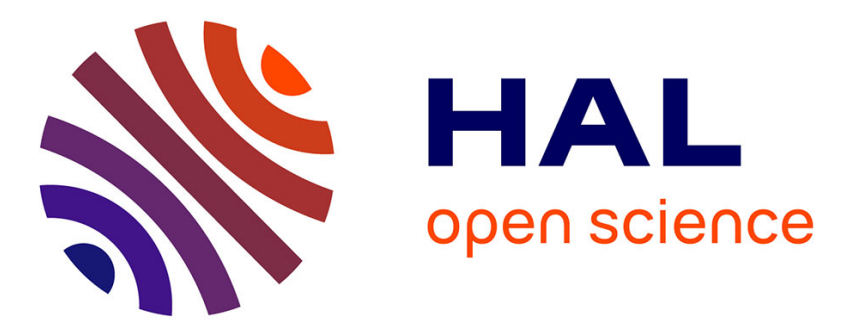

\title{
Solar-Related Variations of the Cloud Top Circulation Above Aphrodite Terra From VMC/Venus Express Wind Fields
}

Marina V. Patsaeva, Igor V. Khatuntsev, L.V. Zasova, Alain Hauchecorne, D.V. Titov, Jean-Loup Bertaux

\section{To cite this version:}

Marina V. Patsaeva, Igor V. Khatuntsev, L.V. Zasova, Alain Hauchecorne, D.V. Titov, et al.. Solar-Related Variations of the Cloud Top Circulation Above Aphrodite Terra From VMC/Venus Express Wind Fields. Journal of Geophysical Research. Planets, 2019, 124 (7), pp.1864-1879. 10.1029/2018JE005620 . insu-02162143

\section{HAL Id: insu-02162143 \\ https://hal-insu.archives-ouvertes.fr/insu-02162143}

Submitted on 4 Mar 2021

HAL is a multi-disciplinary open access archive for the deposit and dissemination of scientific research documents, whether they are published or not. The documents may come from teaching and research institutions in France or abroad, or from public or private research centers.
L'archive ouverte pluridisciplinaire HAL, est destinée au dépôt et à la diffusion de documents scientifiques de niveau recherche, publiés ou non, émanant des établissements d'enseignement et de recherche français ou étrangers, des laboratoires publics ou privés. 


\section{RESEARCH ARTICLE 10.1029/2018JE005620 \\ Key Points: \\ - A maximum deceleration of the mean zonal flow is observed at noon above the highest region of Aphrodite Terra, Venus \\ - The mean zonal and meridional flows at cloud top level in the equatorial region are perturbed by a solar tide at $13-14 \mathrm{hr}$ \\ - A dependence of the mean zonal and meridional flows on topography is observed from the equator to at least $30^{\circ} \mathrm{S}$}

Supporting Information:

- Supporting Information S1

- Data Set S1

- Data Set S2

- Data Set S3

- Data Set S4

- Data Set S5

- Data Set S6

- Data Set S7

- Data Set S8

- Data Set S9

- Data Set S10

- Data Set S11

- Data Set S12

- Data Set S13

- Data Set S14

Correspondence to:

M. V. Patsaeva,

marina@irn.iki.rssi.ru

Citation:

Patsaeva, M. V., Khatuntsev, I. V., Zasova, L. V., Hauchecorne, A., Titov, D. V., \& Bertaux, J.-L. (2019). Solar-related variations of the cloud top circulation above Aphrodite Terra from VMC/Venus Express wind fields.

Journal of Geophysical Research:

Planets, 124, 1864-1879. https://doi. org/10.1029/2018JE005620

Received 19 MAR 2018 Accepted 11 JUN 2019

Accepted article online 20 JUN 2019

Published online 16 JUL 2019

C2019. American Geophysical Union. All Rights Reserved.
Solar-Related Variations of the Cloud Top Circulation Above Aphrodite Terra From VMC/Venus Express Wind Fields

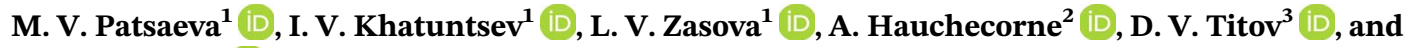 \\ J.-L. Bertaux ${ }^{1,2}$ \\ ${ }^{1}$ Space Research Institute RAS, Moscow, Russia, ${ }^{2}$ LATMOS/INSU/CNRS, UVSQ, Guyancourt, France, ${ }^{3}$ ESA/ESTEC, \\ Noordwijk, The Netherlands
}

Abstract Winds derived by a digital tracking technique from ultraviolet ( $365 \mathrm{~nm}$ ) images captured by the Venus Monitoring Camera (VMC) onboard the Venus Express spacecraft from 2006 to 2013 were used to study the atmospheric circulation at cloud top level $(70 \pm 2 \mathrm{~km})$. This data set allows variations of the wind speed with both latitude and longitude to be studied and establishes their correlation with surface topography as well as local time dependence. Both zonal and meridional wind components show some correlation with topography. The minimum zonal wind speed was found at noon above Ovda Regio $\left(10^{\circ} \mathrm{S}\right.$, $93^{\circ} \mathrm{E}$ ), the highest region of Aphrodite Terra, one of the largest highlands in the equatorial region. The area of slow zonal wind extends to at least $30^{\circ} \mathrm{S}$ and shifts in the direction of superrotation in the afternoon and with increasing latitude (poleward). The observed deceleration of cloud top wind was recently attributed to the interaction of the gravity (mountain) waves generated by Aphrodite Terra with the atmospheric circulation. The present study was performed for different local time over the mountainous longitudes. The deceleration pattern in the zonal wind field is mainly conserved within a few hours around noon. Systematic longitude shift is observed in the afternoon in the direction of the evening terminator. Another area of perturbation of both zonal and meridional wind components is observed in the equatorial region around LT $=13-14 \mathrm{hr}$ and may be explained by the solar tide.

Plain Language Summary Venus is completely covered with a thick cloud layer with its top at about $70 \mathrm{~km}$. Surprisingly, recent observations show that the cloud level circulation is affected by the surface topography. In this paper we analyzed wind velocities derived from tracking of cloud features in the UV images acquired by the Venus Monitoring Camera onboard the European Space Agency's Venus Express orbiter during its operations from 2006 to 2013. The zonal wind at the cloud top decelerates by about $20 \%$ above the highest part of Aphrodite Terra and reaches its minimum at local noon. The zonal wind deceleration is explained by interaction of gravity waves generated by the surface relief with the atmospheric circulation. An additional deceleration occurs in the afternoon in the equatorial region and is probably caused by solar heating of the clouds. The combination of both effects results in a vast area of slow wind during the daytime.

\section{Introduction}

Dynamics of the Venusian atmosphere, in particular, the nature of superrotation, the spatial, temporal, and local time variations of the wind field, and its interaction with the surface, remains one of the most intriguing problems in planetary research. Recent observations suggested an influence of the surface relief on the atmospheric properties at the cloud tops (Bertaux et al., 2016; Fedorova et al., 2016). These results are rather surprising taking into account the great depth and density of the Venus atmosphere. Fukuhara et al. (2017) reported a planetary scale bow-shaped feature observed by the Longwave Infrared (LIR) camera onboard Akatsuki. The feature was meridionally oriented, hemispherically symmetric, and locked to the great highlands on the Venus surface such as Aphrodite Terra, Thesis Regio, Atla Regio, and Beta Regio. Kouyama et al. (2017) found that appearance of the wave depended not only on surface topography but also on latitude and local time.

Signs of the surface-related gravity waves at the cloud top had been previously found in the images captured by the Venus Monitoring Camera (VMC) onboard Venus Express (VEx; Titov et al., 2006; Svedhem et al., 
2009) above Ishtar Terra (Picciali et al., 2014). Tellmann et al. (2009) reported the presence of gravity waves with vertical wavelength of $\sim 4 \mathrm{~km}$ in the temperature profiles in the mesosphere $(60-90 \mathrm{~km})$ derived from VEx's Venus Radio Science radio occultations. Gravity waves with vertical wavelength of 10-14 km and horizontal scale of 100-1,000 km were identified at the mesopause ( 100 km) by Altieri et al. (2014) from the modeling of vertical profiles of the $\mathrm{O}_{2} 1.27 \mu \mathrm{m}$ nightglow emission measured by VEx's Visible and Infrared Thermal Imaging Spectrometer in low-resolution mapping mode at the limb of the planet (Drossart et al., 2007). The influence of surface topography on the atmospheric circulation at 90-100 km was also found by Gorinov et al. (2018) who analyzed apparent motions of the nightglow features. They were typically observed above the mountains, sometimes following the highland's contours or shifted and rotated by a few tens of degrees.

Earlier observations by the Fourier Spectrometer onboard Venera-15 suggested that variations of some atmospheric properties, such as the temperature field at 60-95 km, cloud top altitude, and the wind speed in the midlatitude jet (Zasova et al., 2000), correlate with local time. These variations were described in terms of thermal tide harmonics with amplitude and phase depending on latitude and local time (Zasova et al., 2002, 2007). Later Zasova et al. (2015) found strong correlation of the mesospheric temperature field with topographic features such as Beta Regio, Lakshmi Planum, and Atalanta Planitia.

The surface influence on the atmospheric dynamics was also observed in the middle cloud layer (50-55 km). Peralta et al. (2017) analyzed Visible and Infrared Thermal Imaging Spectrometer in low-resolution mapping mode 3.8- and 5- $\mu \mathrm{m}$ images and detected very slow motions in the middle cloud layer on the night side above the highlands in the southern hemisphere. The strong deceleration of the zonal flow was attributed to the influence of stationary waves generated by the surface. Longitudinal variations of the zonal and meridional wind components in the middle cloud layer on the dayside, claimed by Khatuntsev et al. (2017) from the analysis of VMC near-IR (965 nm) images, could also be explained by stationary waves above Aphrodite Terra.

Unveiling the nature of the superrotation, the structure and variability of the circulation and possible influence of the surface topography requires long-term monitoring of the cloud motions. Imaging of the planet performed by VMC in four channels centered at 365, 513, 965, and 1,010 nm (Markiewicz et al., 2007) provided an excellent opportunity to study the top cloud level circulation during almost 9 years from April 2006 to January 2015. In particular, tracking of the ultraviolet (UV; $365 \mathrm{~nm}$ ) cloud features provided a wealth of information about the cloud top circulation (Khatuntsev et al., 2013; Kouyama et al., 2013; Moissl et al., 2009; Patsaeva et al., 2015).

Khatuntsev et al. (2013) found a gradual increase of the mean zonal wind speed at the cloud top over the course of the VEx mission. In particular, the wind velocity at latitudes of $20^{\circ} \pm 2.5^{\circ} \mathrm{S}$ changed from 85 to $110 \mathrm{~m} / \mathrm{s}$ over 10 Venusian years. Kouyama et al. (2013) also analyzed the VMC data set and derived a similar long-term trend at low latitudes over 6.25 Venusian years. The long-term changes of the zonal flow with a timescale of 5-10 years were claimed by Del Genio and Rossow (1990) from analysis of observations made by the Orbiter Cloud Photopolarimeter on Pioneer Venus. Do these variations indicate long-term changes in the entire cloud top circulation, or do they result from a spatial and/or local time variability of the wind pattern? Bertaux et al. (2016) showed that the variations of zonal wind velocity claimed by Khatuntsev et al. (2013) correlated with the surface topography, indicating wind deceleration downstream of the highlands. The apparent increase of the zonal wind velocity with time reported by Khatuntsev et al. (2013) was understood as an artifact resulting from a combination of the surface-related changes of the wind speed and slow drift of the VEx orbit with respect to the surface topography over the course of the mission. Bertaux et al. (2016) also reported longitudinal variations of the Venus UV albedo and $\mathrm{H}_{2} \mathrm{O}$ abundance related to Aphrodite Terra, the largest highland in the equatorial region.

All in all, the above-mentioned observations and their analysis indicated significant correlation of the cloud level winds and other parameters of the upper atmosphere with the surface topography. Several authors suggested gravity waves generated by the relief features and propagating upwards to the cloud level as a possible explanation of this correlation. They followed the approach of Lindzen (1981) who explained deceleration of the zonal wind in the Earth's mesosphere by breaking of gravity waves. However, mechanisms of generation and propagation of gravity waves in the thick and dense atmosphere of Venus, and their interaction with the superrotating flow, are poorly understood. Gravity waves can propagate only in a stable atmosphere and are destroyed by instabilities. Observations show that the Venus atmosphere is a complex "sandwich" of stable 
Table 1

VMC Orbits Used for Tracking of UV Cloud Features in This Work

\begin{tabular}{|c|c|c|}
\hline $\begin{array}{l}\text { Data set } \\
\text { Number }\end{array}$ & $\begin{array}{l}\text { Date of observations } \\
\quad \text { (begin to end) }\end{array}$ & Orbits \\
\hline 1 & $2006-06-19$ to $2006-07-03$ & $0060,0073,0074$ \\
\hline 2 & $2006-12-18$ to $2007-02-13$ & $0241,0246,0253,0254,0258,0263,0265,0266,0267,0280,0281,0283,0284,0285,0289,0290,0291,0295,0297,0298$ \\
\hline 3 & 2007-06-30 to 2007-09-10 & $\begin{array}{l}\text { 0436, 0437, 0441, 0443, 0445, 0446, 0452, 0457, 0458, 0461, 0462, 0465, 0469, 0470, 0471, 0472, 0474, 0475, 0480, 0481, 0484, } \\
\text { 0485, 0497, } 0508\end{array}$ \\
\hline 4 & 2008-01-21 to 2008-05-09 & $\begin{array}{l}0641,0649,0653,0655,0656,0662,0664,0669,0672,0674,0678,0679,0682,0686,0688,0689,0690,0692,0694,0696,0697 \text {, } \\
\text { 0699, 0702, 0704, 0708, 0717, 0718, 0722, 0723, 0727, 0728, 0731, 0734, 0748, } 0749\end{array}$ \\
\hline 5 & 2008-09-04 to $2008-12-15$ & $\begin{array}{l}\text { 0868, 0871, 0872, 0875, 0876, 0877, 0879, 0880, 0882, 0884, 0887, 0889, 0892, 0893, 0894, 0895, 0898, 0900, 0901, 0902, 0903, } \\
\text { 0906, 0910, 0911, 0913, 0914, 0916, 0919, 0920, 0922, 0924, 0926, 0931, 0932, 0933, 0936, 0937, 0938, 0940, 0942, 0963, } \\
\text { 0964, 0966, 0967, 0969 }\end{array}$ \\
\hline 6 & 2009-04-14 to 2009-07-26 & $\begin{array}{l}1090,1093,1094,1099,1102,1103,1104,1105,1107,1108,1109,1112,1113,1114,1117,1118,1120,1121,1122,1123,1126 \text {, } \\
\quad 1127,1131,1171,1172,1177,1179,1184,1185\end{array}$ \\
\hline 7 & $2009-11-19$ to $2010-02-19$ & $\begin{array}{l}1309,1312,1315,1320,1325,1332,1335,1336,1340,1341,1342,1343,1344,1345,1346,1375,1377,1380,1386,1391,1398, \\
\quad 1400\end{array}$ \\
\hline 8 & $2010-08-28$ to $2010-10-13$ & $1591,1594,1596,1597,1604,1613,1636$ \\
\hline 9 & $2011-02-23$ to $2011-05-05$ & $1770,1774,1782,1786,1795,1796,1802,1804,1812,1815,1816,1818,1822,1823,1827,1828,1840$ \\
\hline 10 & $2011-10-05$ to $2011-12-15$ & 1994, 1996, 2014, 2031, 2032, 2034, 2037, 2040, 2042, 2044, 2047, 2048, 2049, 2050, 2052, 2053, 2059, 2062, 2064 \\
\hline 11 & $2012-05-18$ to $2012-08-01$ & $2220,2221,2223,2224,2225,2226,2227,2231,2233,2258,2262,2264,2268,2273,2280,2281,2283,2287,2291,2293,2295$ \\
\hline 12 & $2012-12-23$ to $2013-01-27$ & $2439,2441,2442,2453,2454,2456,2466,2469,2472,2473$ \\
\hline 13 & 2013-07-07 to 2013-09-15 & $2659,2663,2667,2674,2680,2686,2691,2695,2697,2705$ \\
\hline All & 2006-06-19 to 2013-09-15 & 0060-2705 \\
\hline
\end{tabular}

Note. $\mathrm{VMC}=$ Venus Monitoring Camera; UV = ultraviolet. Dates are formatter as YYY-MM-DD.

and unstable (or marginally stable) layers whose vertical structure is not well known, especially below $40 \mathrm{~km}$ (Limaye et al., 2018). Bertaux et al. (2016) explained the observed deceleration of the zonal wind (Khatuntsev et al., 2013) by the influence of stationary gravity waves. The authors suggested that the orographic (mountain) gravity waves generated by large highland provinces propagate upward up to the cloud level where they break and transfer their momentum to the general circulation thus slowing down the zonal flow. The global bow-shape signature (Fukuhara et al., 2017) was interpreted as a stationary wave. This feature was reproduced by a Venus General Circulation Model (GCM) (Navarro et al., 2018).

In this paper we continue the study by Bertaux et al. (2016) of the influence of the surface topography on the cloud top circulation. We used the digital correlation method to derive the wind velocity field from the full set of UV images taken by the VMC camera onboard ESA's VEx orbiter, with data collected from 2006 to 2013. This paper presents the cloud top wind field and its variations with latitude, longitude, and local solar time focusing on the influence of the surface topography and, in particular, Aphrodite Terra.

\section{VMC Data Set}

The VMC camera experiment onboard VEx was described in full by Markiewicz et al. (2007) and Titov et al. (2012). VEx operated in an elliptical polar orbit with an apocenter at $66000 \mathrm{~km}$ approximately above the southern pole and a period of about $24 \mathrm{hr}$. The orbit enabled VMC observations of the southern hemisphere every $24 \mathrm{hr}$ with good illumination conditions (see details in Khatuntsev et al., 2013). Optimal imaging conditions occurred in specific periods ("seasons") when the spacecraft was approaching the dayside in the ascending arc of the orbit. Typical spatial resolution of these observations was 10-50 km per pixel, which made them well suited for investigation of the global circulation.

More than 170,000 wind vectors were derived by digital cloud tracking from the VMC UV images (Patsaeva et al., 2015) acquired in 262 orbits in 2006-2013. In this paper we study the cloud top circulation in the equatorial region and its variability. More than 44,000 wind vectors were derived from tracking cloud features in the UV images in the latitude band $0-30^{\circ} \mathrm{S}$. Most of the measurements with uniform latitude-longitude coverage correspond to the first half of the mission. The number of orbits available in the second half of the mission is twice as small. Smaller number and poorer quality of the images in the second half of the mission resulted in sparser spatial coverage especially in equatorial regions. In particular, the coverage of Aphrodite Terra is worse than that of the surrounding regions. The VMC data set used in this work is presented in Table 1. 
Table 2

Number of Individual Wind Vectors in Data Bins

\begin{tabular}{lc}
\hline Solar local time interval & $\begin{array}{c}\text { Number of individual wind } \\
\text { vectors } 0-90^{\circ} \mathrm{S} / 0-30^{\circ} \mathrm{S}\end{array}$ \\
\hline $10-11$ & $27291 / 7623$ \\
$11-12$ & $32328 / 7488$ \\
$12-13$ & $35763 / 8220$ \\
$13-14$ & $34612 / 10387$ \\
$14-15$ & $21389 / 8120$ \\
$15-16$ & $6110 / 2372$ \\
\hline
\end{tabular}

\section{Results}

The digital method of cloud tracking (Khatuntsev et al., 2013; Patsaeva et al., 2015) provided a much larger number of individual wind measurements than the manual tracking method. It significantly improved the data statistics and allowed a detailed investigation of the mean wind field at cloud top level as a function of longitude, latitude and local time.

\subsection{Solar Position-Related Dependence of the Mean Zonal Flow}

We found earlier (Bertaux et al., 2016) a marked dependence of the zonal wind speed on the longitude over Aphrodite Terra (a large region of mountainous terrains), in the latitude band $0-30^{\circ} \mathrm{S}$. This was done with a day side data set collected over a large local time in the interval $08-17 \mathrm{hr}$ LT. Here we wish to see if the local time has any influence on the wind field pattern in this region that is particularly well covered with the VMC data set. The large number of individual wind measurements obtained by the digital method of cloud tracking (Patsaeva et al., 2015) enabled this investigation of the local time dependence of the zonal wind speed pattern. To begin with, the data were grouped in 1-hour local solar time bins. The number of vectors in each local time bin is shown in Table 2.

A complete spatial coverage within each bin allows us to plot maps of the mean zonal velocity for the selected local time intervals (Figure 1). The plots show the evolution of the zonal wind field with local time. The most pronounced feature is the area of reduced wind speed above and downstream of Aphrodite Terra with velocities of $-84 \pm 2 \mathrm{~m} / \mathrm{s}$, the shape of which changes with local time. At 10-11 hr the low-speed region

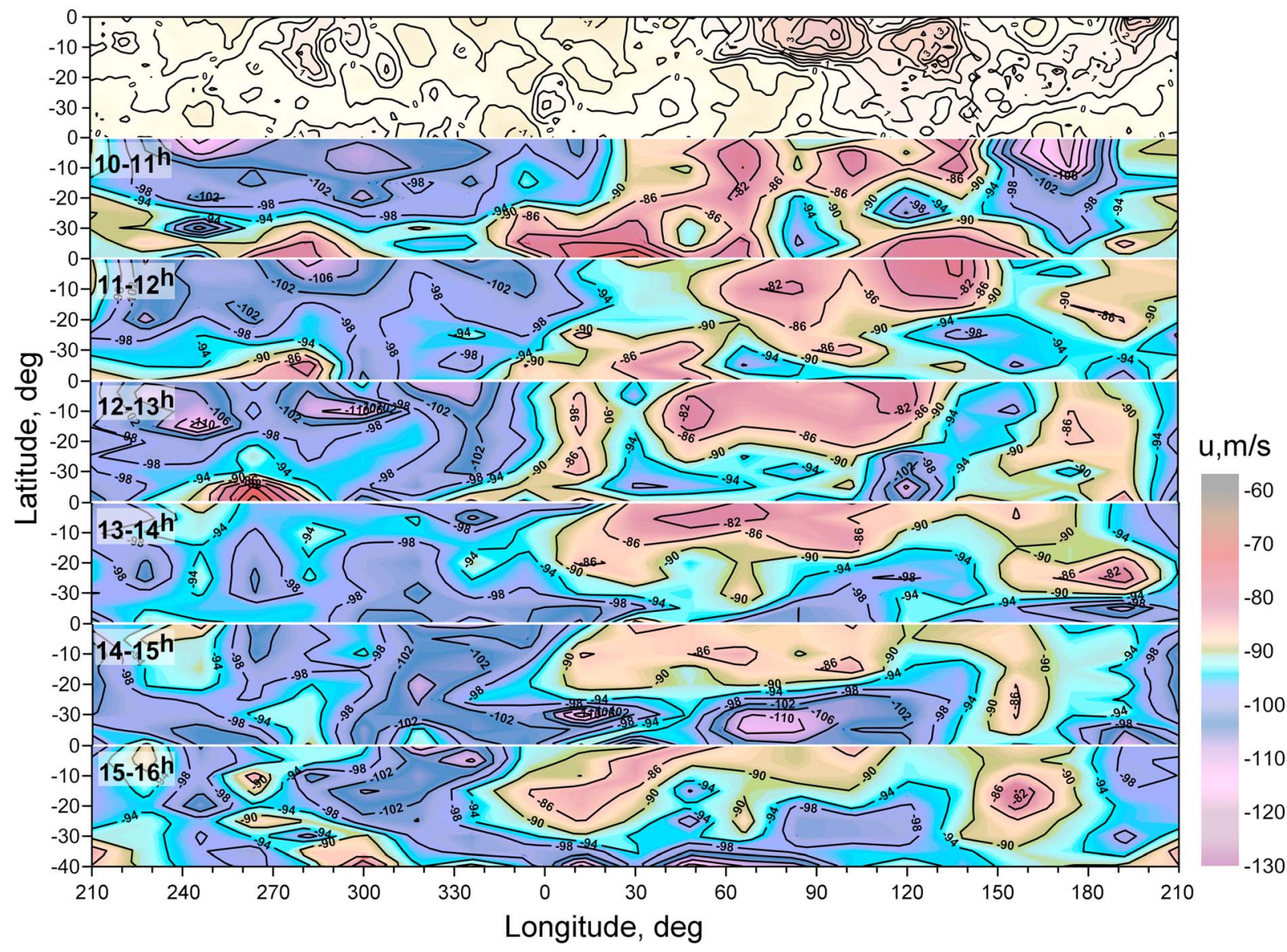

Figure 1. Spatial distribution of the average zonal wind speed at the cloud top plotted for 1-hr local time intervals (Table S1). The local time is the same for all points in the wind maps; it is indicated in the upper left corner of each panel. Therefore, these "maps" are not actual, instantaneous maps of the wind field. Topographic maps from National Aeronautics and Space Administration Magellan mission are presented in the upper panel. 

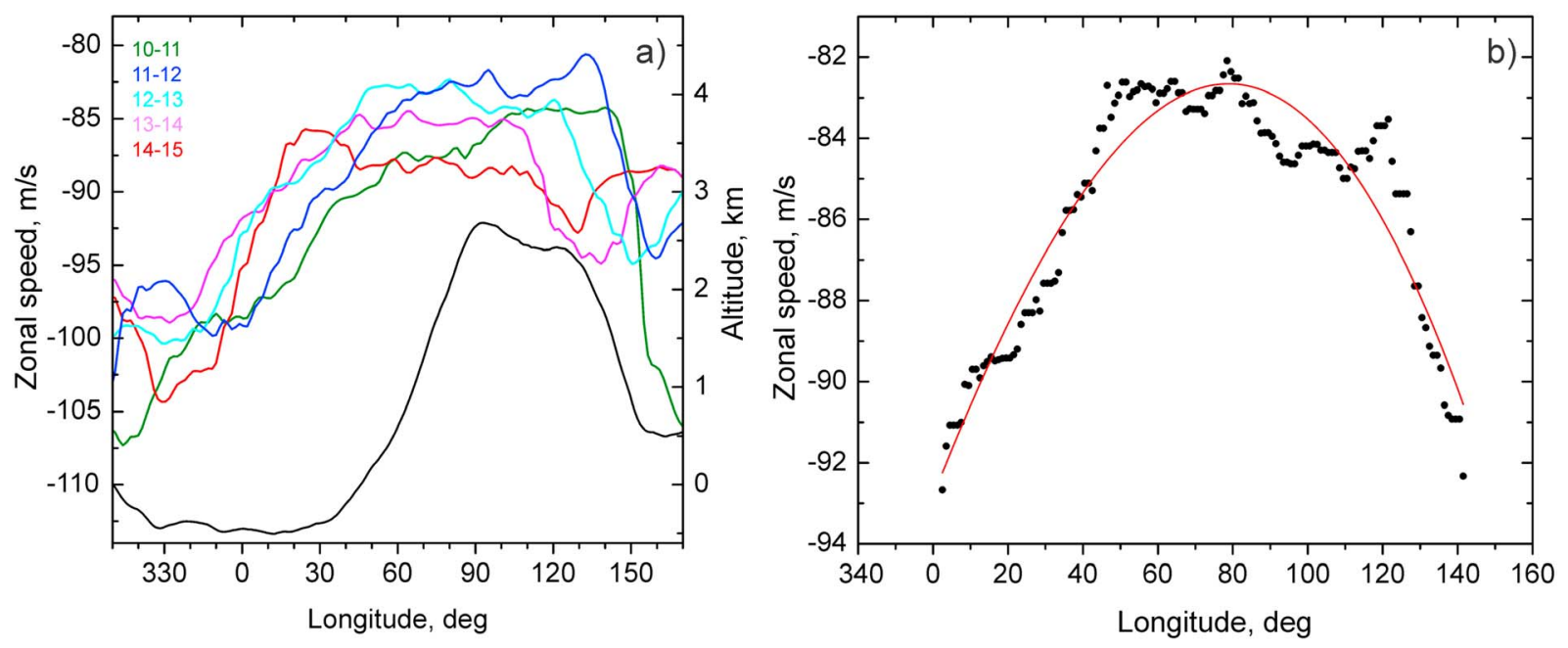

Figure 2. Mean profiles of surface altitude (black line) and zonal wind speed for different local time intervals averaged in latitude band $10 \pm 5^{\circ} \mathrm{S}$ (color lines; Table S1). The local time intervals corresponding to the line color are indicated in the upper left corner. Note that due to the negative sign of the wind velocity, the minimum wind speed (the slowest zonal wind) corresponds to an apparent maxima in the wind profiles (a); example of fitting of the wind profile at 12-13 hr (black data points correspond to the cyan line the left panel) by a Gauss function (red line; b).

spreads over a wide longitude range. By noon (11-12 hr) the wind feature becomes more pronounced. In the afternoon the feature is deformed and stretched downstream of Aphrodite Terra in the direction of superrotation.

We focus the study on the Aphrodite Terra region above which the most pronounced diurnal variability of the zonal wind pattern was found (Figure 1). Longitudinal profiles of the mean zonal wind speed were built for the selected local time bins for the latitude band of $10 \pm 5^{\circ} \mathrm{S}$ that includes Ovda Regio, the highest part of Aphrodite Terra (Figure 2). The figure shows the mean profile of the surface topography and average profiles of the zonal wind speed for different 1-hr local time intervals in the latitude band $10 \pm 5^{\circ} \mathrm{S}$. Each point is an average of all vectors within the latitude band $10 \pm 5^{\circ} \mathrm{S}$ and a longitude bin of $30^{\circ}$ (sliding average). The five curves, one for each 1-hr LT bin, show the same overall pattern of a strong deceleration of the zonal wind over high relief areas and then a reacceleration over the plains (longitude $0^{\circ}$ to $\sim 50^{\circ}$ ). This is the pattern that was detected earlier in Bertaux et al. (2016) with a smaller data set and with all LT mixed together. The fact that with more data, split into five independent data sets sorted by local time, the same overall deceleration pattern is observed confirms that this deceleration pattern is a robust finding and confirms the earlier detection of Bertaux et al. (2016). However, here we are interested in the differences between the five curves. The zonal wind profiles at different local times show changes in the longitude of velocity minimum (absolute value, or modulus value) and its shift with respect to the highest point in Ovda Regio. The range of local time variations of the mean zonal wind speed at $90^{\circ} \mathrm{E}$ is about $13 \mathrm{~m} / \mathrm{s}$. The standard error of the mean for all profiles does not exceed $1.5 \mathrm{~m} / \mathrm{s}$ thus showing statistical significance of the observed shift feature with local time. In addition, a dichotomy exercise was performed as explained in Appendix A, in which data were separated into two groups: those with velocity vectors faster than the average, and velocity vectors slower than the average. The same characteristics are found for the two separate groups, showing the robustness of the findings: a deceleration of the zonal wind above or downstream of the Aphrodite Terra highlands, with a downstream shift of the deceleration when local time changes from 10-11 to 15-16 hr (see Appendix A for details).

To determine the slowest wind longitude above Aphrodite Terra (Figure 2) for each local time bin we used the longitude range from $0^{\circ}$ to $160^{\circ} \mathrm{E}$. The parts of the curves with $u>-93 \mathrm{~m} / \mathrm{s}$ were approximated by a Gaussian function using a least square fit technique (Figure $2 \mathrm{~b}$ ). The longitude of the slowest zonal wind was defined as the position of the Gaussian extremum. The wind velocity value was determined by averaging over the longitude range with $u>-93 \mathrm{~m} / \mathrm{s}$. This procedure was repeated for local time samples separated by half an hour intervals (see examples in Figure 2). Figure 3 shows the resulting positions of the slowest wind as a function of longitude. 


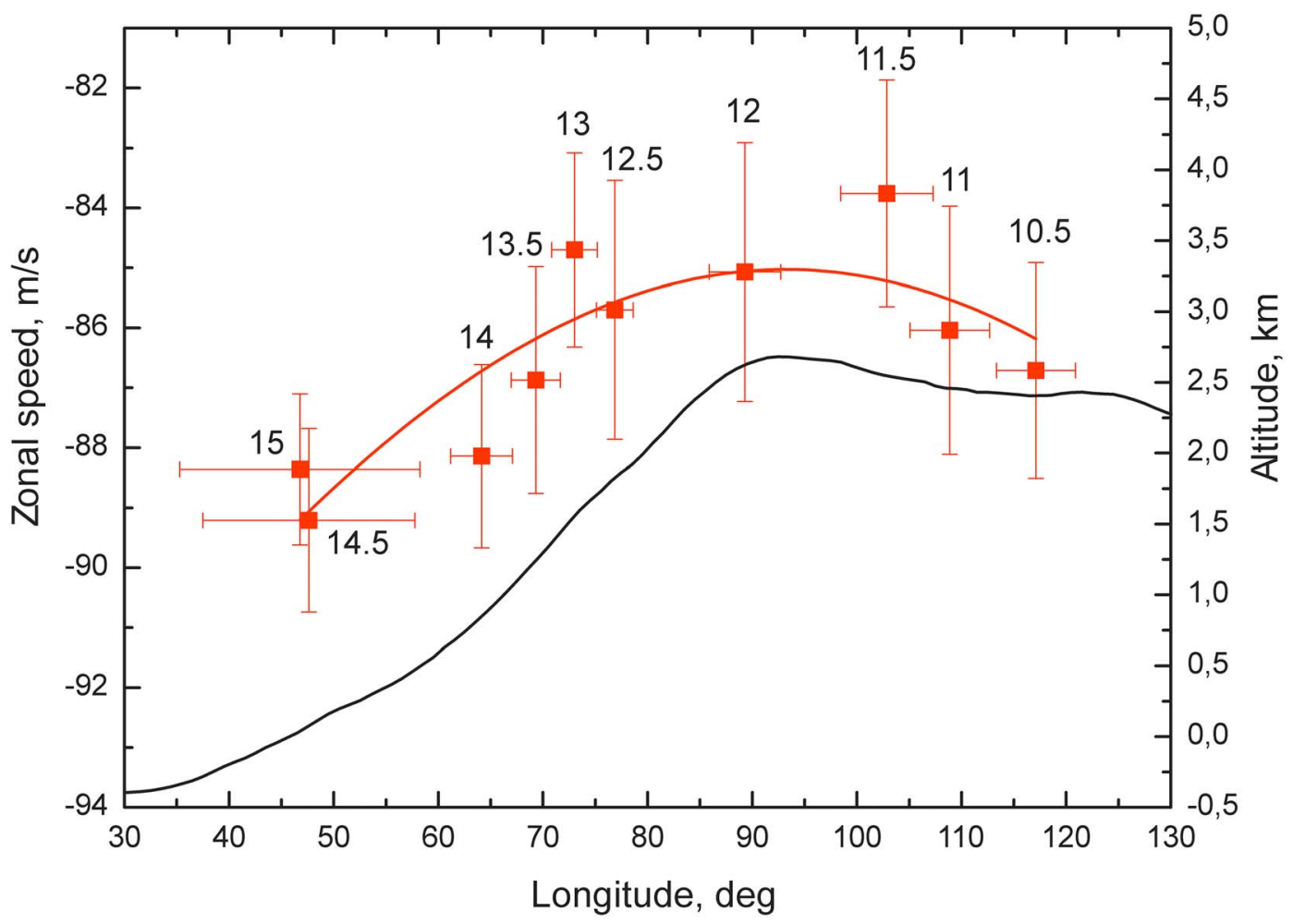

Figure 3. Positions of the minimum of the mean zonal speed for different local time intervals (red squares) above Aphrodite Terra as a function of longitude (Table S3). The error bars correspond to confidence intervals ( $3 *$ SEM, where SEM is standard error of the mean) or $99.7 \%$ confidence levels. The black line shows the mean surface topography at $10 \pm 5^{\circ} \mathrm{S}$.

The dependence of the position of minimum zonal speed on longitude in Figure 3 was approximated by a sine wave:

$$
\left.u(\lambda)\right|_{\lambda \in[45 ; 120]}=-98.5-13.4 \sin (\lambda-183.2)
$$

where $\left.u\right|_{\lambda \in[45 ; 120]}$ is the approximate zonal speed as function of longitude $\lambda$ in the range of $45-120^{\circ} \mathrm{E}$.

This function peaks at $-85 \mathrm{~m} / \mathrm{s}$ at about $93^{\circ} \mathrm{E}$, which coincides with the highest point on the surface. This wind velocity minimum (in modulus) is reached above Ovda Regio $\left(90 \pm 5^{\circ} \mathrm{E}\right)$ at noon local time. Apparently, the deceleration of the zonal wind in the $10 \pm 5^{\circ} \mathrm{S}$ latitude band is local time dependent, being weaker in the afternoon and possibly before noon.

\subsection{Latitude-Longitude Variations of Mean Zonal Wind}

Longitudinal profiles of the mean zonal wind speed (similar to those in Figure 2) were plotted for $10^{\circ}$ latitude bands centered at $7,12,15,17,20,22$, and $25^{\circ} \mathrm{S}\left(7 \pm 5^{\circ} \mathrm{S}, 12 \pm 5^{\circ} \mathrm{S}\right.$, etc. $)$ and 1 -hr local time intervals. Three time intervals 11-12, 12-13, and 13-14 hr were chosen for this exercise (Figure 4).

Figure 4 shows that the wide minimum of the wind speed modulus at $10 \pm 5^{\circ} \mathrm{S}$ correlates with the surface altitude in the region of Aphrodite Terra $\left(0-150^{\circ} \mathrm{E}\right)$. The correlation is observed to persist at least down to $30^{\circ} \mathrm{S}$, although the wind profile gradually shifts downstream of Aphrodite Terra while the wind speed increases (in absolute values) with latitude by about $5 \mathrm{~m} / \mathrm{s}$ at $30^{\circ} \mathrm{S}$. Thus, the slowing down of the zonal flow caused by Aphrodite Terra is traced from the equator to at least $30^{\circ} \mathrm{S}$. The maximal deceleration of wind occurs at 11-12 hr above the maximal altitude of Aphrodite Terra (Ovda Regio) located at $10 \pm 5^{\circ} \mathrm{S}$ and 90 $\pm 5^{\circ} \mathrm{E}$.

The longitude profiles of the zonal winds in each latitude band were averaged over local time, as displayed on Figure 5a. The data coverage is uniform with respect to local time in all latitude bands, so we used a total local time interval from 9 to $16 \mathrm{hr}$ for better statistics. Each longitude profile was approximated by a 


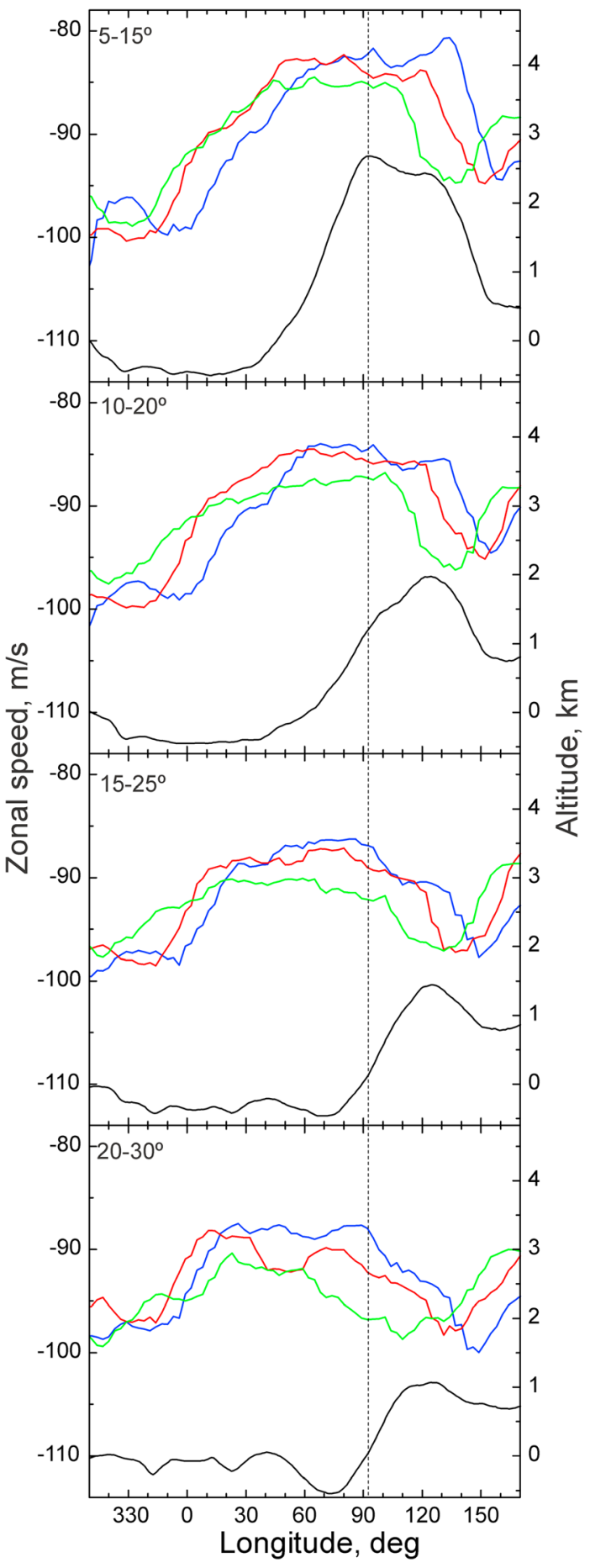

Figure 4. Longitudinal mean profiles zonal wind speed for $10^{\circ}$ latitude bands centered at $10^{\circ}, 15^{\circ}, 20^{\circ}$, and $25^{\circ} \mathrm{S}$ and three local time intervals $11-$ $12 \mathrm{hr}$ (blue), 12-13 hr (red), and 13-14 hr (green; Table S4). The standard error of the mean is not more than $1.5 \mathrm{~m} / \mathrm{s}$. Black lines show the mean surface topography in the latitude bands. The vertical dotted line shows position of the topography maximum in the first band $\left(5-15^{\circ} \mathrm{S}\right)$.
Gaussian function to determine the minimum speed longitude. Figure $5 \mathrm{~b}$ shows a fragment of the Venus topographic map with Aphrodite Terra with red circles marking positions of the minima. This figure suggests that the location of the zonal wind minimum (modulus), or peak, shifts downstream and the deceleration of the zonal wind decreases as we move south.

\subsection{Latitude-Longitude Variations of Mean Meridional Flow}

Figure 6 shows longitudinal profiles of the mean meridional wind for two $10^{\circ}$ latitude bands centered at $7^{\circ} \mathrm{S}$ and $25^{\circ} \mathrm{S}$. The former encompasses Aphrodite Terra while the latter crosses lowlands. Their comparison reveals the influence of the mountains on the meridional wind. The meridional component depends on both surface topography and local time. In order to average out the local time dependence we used all available data within the time interval from 9 to $16 \mathrm{hr}$. To take into account the increase of meridional component with latitude and facilitate the comparison, we subtracted a mean meridional speed-of $-0.5 \mathrm{~m} / \mathrm{s}$ for $7^{\circ} \mathrm{S}$ and $-4.4 \mathrm{~m} / \mathrm{s}$ for $25^{\circ} \mathrm{S}$ from the longitudinal profiles. The mean global meridional wind profiles were also derived from VMC observations (Figure 10b in Khatuntsev et al., 2013). Negative values indicate southward meridional winds.

The difference between the profiles in Figure 6 in the longitude range 60$250^{\circ} \mathrm{E}$ exceeds $99.7 \%$ confidence interval and is statistically significant. This indicates that the vast equatorial highlands from Atla Regio to Aphrodite Terra perturb the meridional winds with an amplitude up to $3.5 \mathrm{~m} / \mathrm{s}$.

\subsection{Role of Solar-Related Effects in Variations of the Horizontal Flow}

Averaging over the entire observation period of 7.25 years eliminates short-term variations (4-5 days) caused by the superrotation and the influence of the "Y" or "V" patterns of UV marks and wind fields. The large number of individual velocity vectors allowed zonal and meridional speed variations to be investigated as a function of longitude, latitude and local time. We considered three $60^{\circ}$ longitude intervals $10-70^{\circ} \mathrm{E}, 35-95^{\circ} \mathrm{E}$ and $55-115^{\circ} \mathrm{E}$ containing noon. The panels in Figure 7 show views of the circulation at the cloud top averaged over the entire mission with noon at various longitudes with respect to Aphrodite Terra. They may be considered as instantaneous wind field maps recorded when the sun is just over three different longitudes, within $\pm 7.5^{\circ}$ (corresponds to $\pm 0.5 \mathrm{hr}$ of LT).

A strong deceleration of the zonal flow is found around noon above Ovda Regio (Figure 7a). We attribute the wind deceleration to the influence of stationary mountain wave on the zonal flow as suggested in Bertaux et al. (2016). Figure 7a suggests indeed a strong correlation of the slow wind region with surface topography when noon coincides with highlands. The displacement of the "noon" line from the highlands results in a stretching of the slow speed area and its shifting to the afternoon (Figure $7 b$ ). In contrast, there is no visible zonal wind deceleration when the noon meridian is above lowlands (Figure 7c).

We examined variations of the zonal and meridional wind components with local time for longitude intervals corresponding to Ovda Regio (60$110^{\circ} \mathrm{E}$ ) and the lowland region $\left(335-25^{\circ} \mathrm{E}\right.$ ) separately (Figures $8 \mathrm{c}$ and $8 \mathrm{f}$, respectively). This allows us to separate topography and solar time related effects. Mean local time profiles of the zonal and meridional 


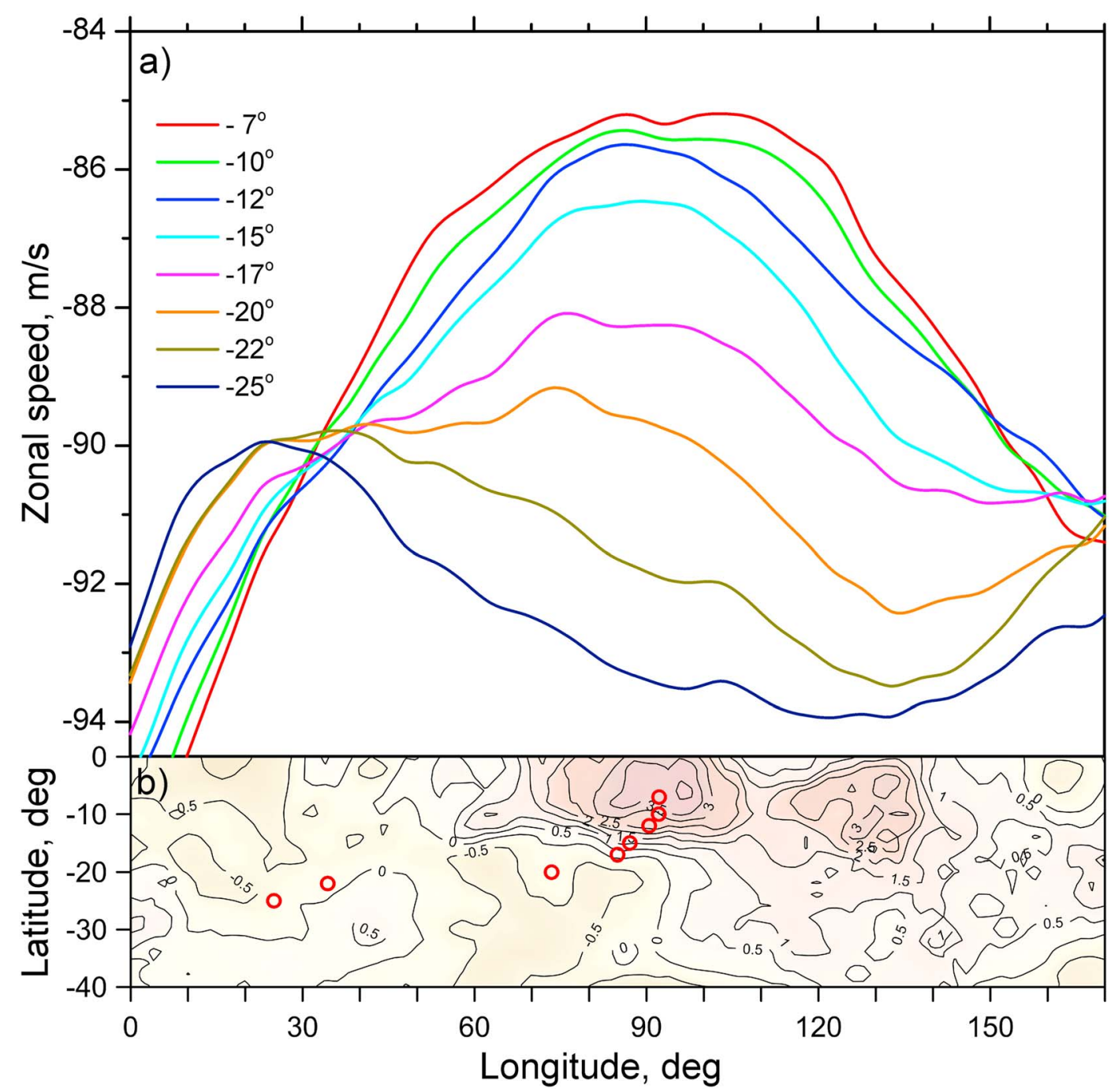

Figure 5. Averaged over local time (from 9 to $16 \mathrm{hr}$ ) profiles of zonal wind speed for $10^{\circ}$ latitude bands centered at $7^{\circ} \mathrm{S}, 10^{\circ} \mathrm{S}, 12^{\circ} \mathrm{S}, 15^{\circ} \mathrm{S}, 17^{\circ} \mathrm{S}, 20^{\circ} \mathrm{S}, 22^{\circ} \mathrm{S}$, and $25^{\circ} \mathrm{S}$ (Table S5). The standard error of the mean is less than $0.4 \mathrm{~m} / \mathrm{s}(\mathrm{a})$; positions of extremums of longitudinal average profiles of zonal wind (red circles) on the Venus topographic map with altitudes in kilometers (b).

speeds for two $10^{\circ}$ latitude bands centered at $7^{\circ} \mathrm{S}$ and $25^{\circ} \mathrm{S}$ are shown in Figure 8. Figures $8 \mathrm{a}$ and $8 \mathrm{~b}$ correspond to the topographic highs, while Figures $8 \mathrm{~d}$ and $8 \mathrm{e}$ show the wind profiles above the lowlands.

We first compare the two red lines of Figures $8 \mathrm{a}$ and $8 \mathrm{~d}$, which are the zonal wind curves at $7^{\circ} \mathrm{S}$ as a function of local time over highland (Figure 8a, red line) and over lowland (Figure 8d, red line). Both show a pattern of variation with local time much larger than the error bars. The speed (modulus values) is much smaller over highlands than over lowlands, an effect of zonal wind deceleration over highlands. This deceleration has a broad maximum around noon over highlands, wider than the similar extrema over lowlands. It is interesting to compare with the 3-D simulations of thermal tides made by Takagi et al. (2018), despite the fact that their model has some limitations (no topography, simplified infrared radiative process represented by Newtonian cooling, small-scale dynamics processes represented by Rayleigh friction), and hence, we cannot expect a perfect representation of the tides. The model (Figure 2a in Takagi et al., 2018) predicts a minimum of the zonal wind around noon at the equator, in agreement with our observations.

For meridional wind speed (Figures $8 \mathrm{~b}$ and $8 \mathrm{e}$, red lines), the variations with local times are similar for highlands and lowlands. The meridional speed above Ovda Regio near the equator (Figure 8b, red line) has a visible extremum at 13-14 hr when the meridional flow changes direction from southward to northward. A similar behavior can be seen above lowlands (Figure 8e). The minimum (in absolute values) of the zonal 


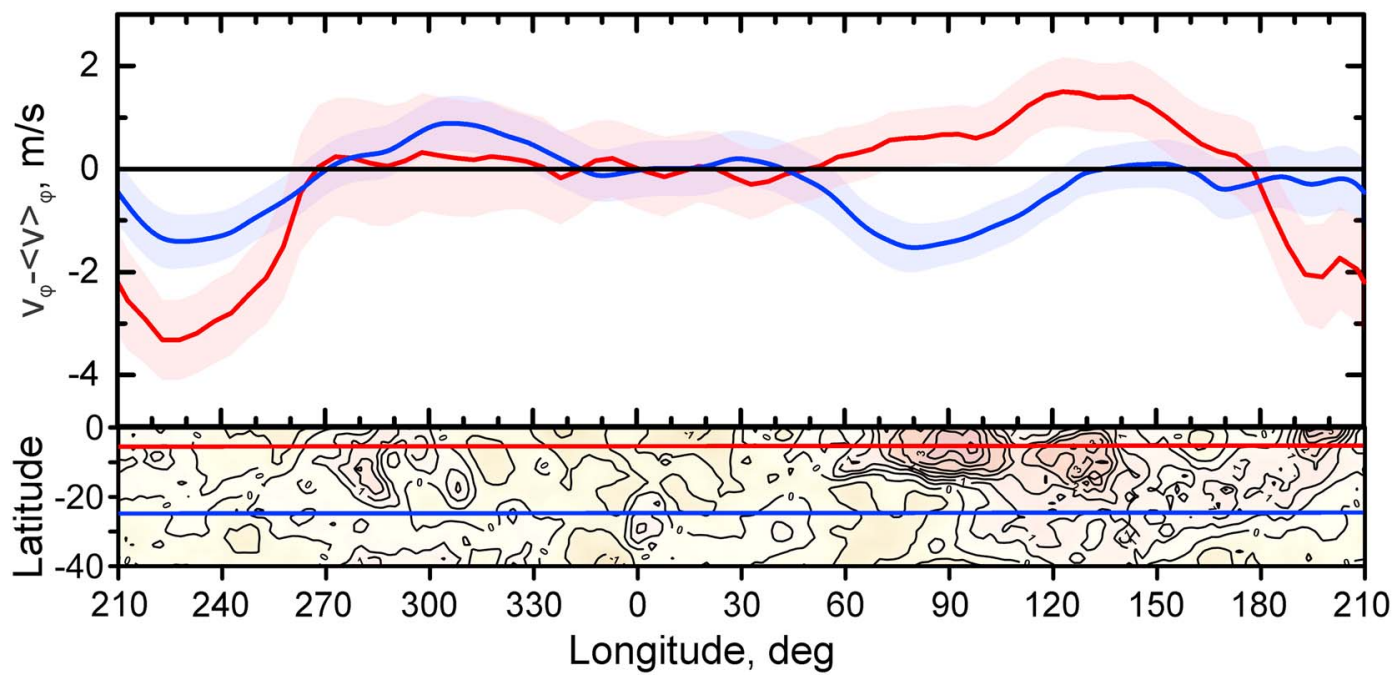

Figure 6. Longitudinal profiles of the difference between meridional wind speed $v_{\varphi}$ for $10^{\circ}$ latitude bands centered at $7^{\circ} \mathrm{S}$ (red) and $25^{\circ} \mathrm{S}$ (blue) and the meridional speed $\langle\nu\rangle_{\varphi}$ averaged over the time interval 9-16 hr and all longitudes $(-0.5 \mathrm{~m} / \mathrm{s}$ for $7^{\circ} \mathrm{S}$ and $-4.4 \mathrm{~m} / \mathrm{s}$ for $25^{\circ} \mathrm{S}$; Table S6). The shadowed areas denote the errors and correspond to $3 * \mathrm{SEM}$ (a); Venus topographic map with red and blue lines marking $7^{\circ} \mathrm{S}$ and $25^{\circ} \mathrm{S}$ correspondingly (b). SEM $=$ standard error of the mean

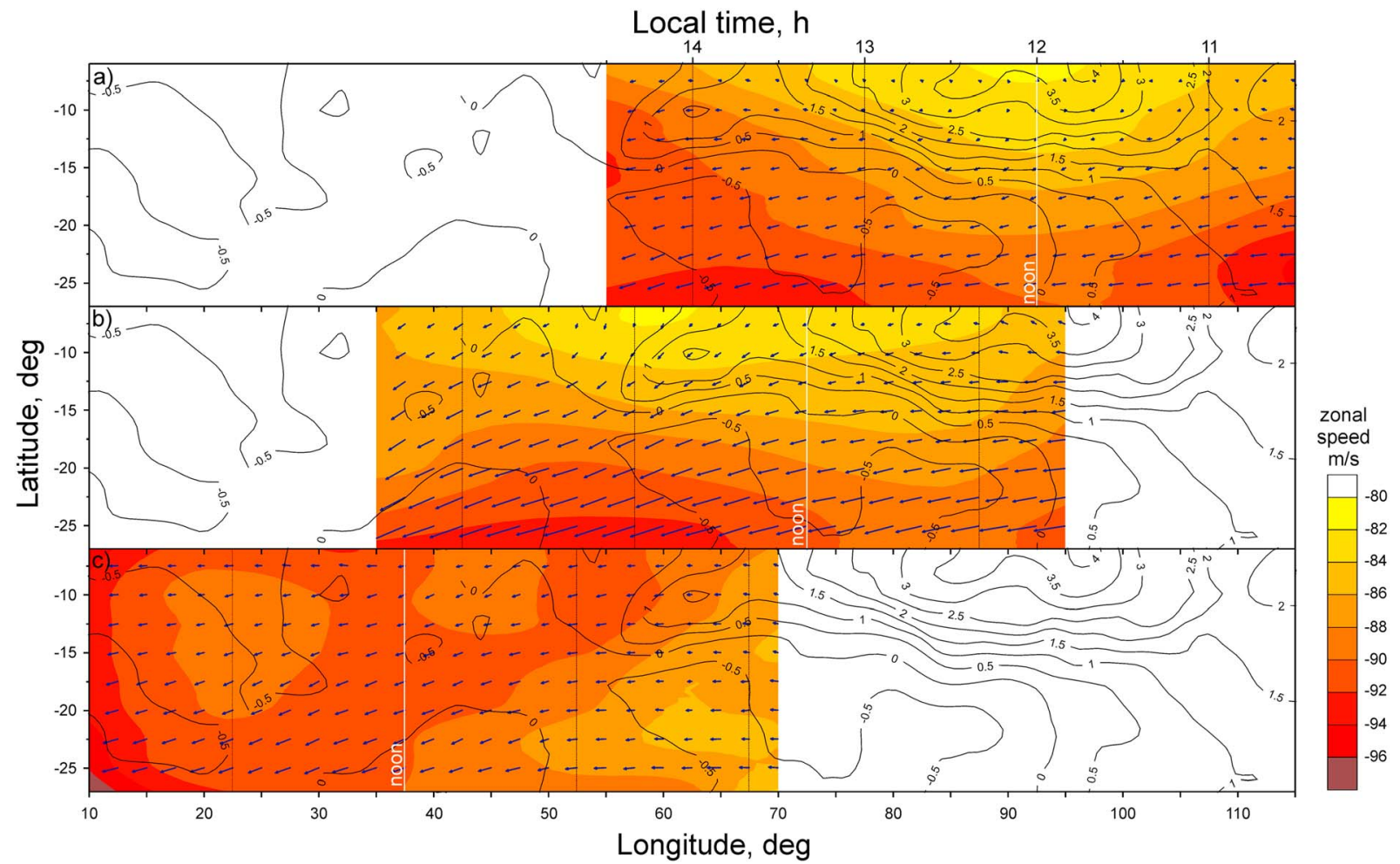

Figure 7. Mean wind field as a function of longitude and local time (Tables S7-S9). The data were averaged over the entire observation period. The wind fields as a function of longitude and local time were calculated by averaging over $\left[15^{\circ}, 10^{\circ}\right]$ bins (longitude, latitude) with a shift of $2.5^{\circ}$ in longitude and latitude. Variations of the zonal speed are shown in color. Vectors represent the wind field after subtraction of the mean zonal wind $u_{0} \cdot \cos (\varphi)$ where $u_{0}=-81.5 \mathrm{~m} / \mathrm{s}$ and $\varphi$ is latitude. The subtraction is made to make the flow direction more pronounced. The surface topography is shown as black contours. The "noon" line (white) corresponds to $92.5^{\circ} \mathrm{E}(\mathrm{a}), 72.5^{\circ} \mathrm{E}(\mathrm{b})$, and $37.5^{\circ} \mathrm{E}$ (c) longitudes. The local times in the upper panel correspond only to the upper panel (a). 

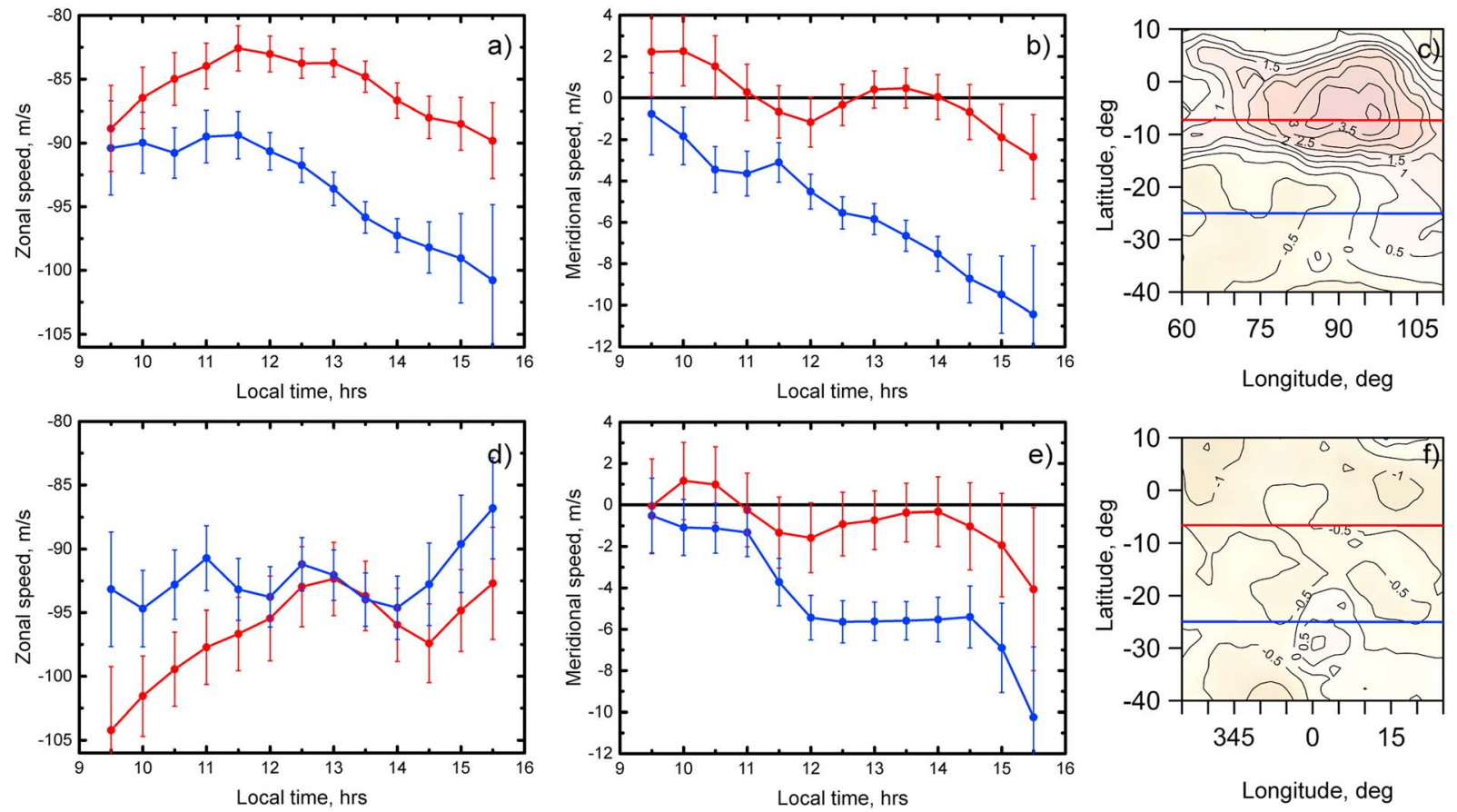

Figure 8. Mean local time profiles of the zonal (a, d) and meridional (b, e) speeds for two $10^{\circ}$ latitude bands centered at $7^{\circ}$ (red) and $25^{\circ} \mathrm{S}$ (blue) for highland Ovda Regio $\left(60-110^{\circ} \mathrm{E} ; \mathrm{c}\right)$ and the lowland region $\left(335-25^{\circ} \mathrm{E}\right.$; f; Tables S10 and S11). The data were averaged over 1-hr local time with a shift of $0.5 \mathrm{hr}$. The error bars correspond to $3 *$ SEM. SEM $=$ standard error of the mean.

speed above the lowland at $7^{\circ} \mathrm{S}$ (red line) on Figure $8 \mathrm{~d}$ is located near $13 \mathrm{hr}$, that is, about the same time as the extremum of the meridional component. We tentatively attribute these extremes at 13-14 hr to solar tides.

The zonal wind speed above Ovda Regio at $7^{\circ} \mathrm{S}$ (red line in Figure 8a) decreases in daylight hours showing a wide zone of slow wind as noted above. A comparison of the wind profiles in Figures 8a (highlands) and 8d (lowlands) suggests that the topography related zonal speed minimum above Ovda Regio is more prominent above the topographic highs. This minimum is more pronounced at noon (see section 3.1). We attribute the minimum at $13 \mathrm{hr}$ in Figure $8 \mathrm{~d}$ to the solar tide. Assuming that the solar tide above Ovda Regio has a similar local time span and localization, we expect that the decrease of the zonal speed caused by the tide and that due to topography would merge, resulting in a wide minimum between 11 and $14 \mathrm{hr}$ (Figure 8a, red line).

The difference between blue and red lines in Figure 8a is greater than that in Figure 8d due to higher elevation changes in Ovda Regio. The zonal speed above lowland at $25^{\circ} \mathrm{S}$ (Figure 8d, blue line) has no discernable extremes within the limits of experimental error. Note that the blue line on Figure 8a does not have a pronounced minimum in the afternoon (13-14 hr). But the minimum (modulus) at 11-12 hr in Figure 8a (blue line) is caused by the influence of Ovda Regio topography onto the zonal flow at $25^{\circ} \mathrm{S}$ latitude (see Figure 4).

The meridional speed profiles at $7^{\circ} \mathrm{S}$ and $25^{\circ} \mathrm{S}$ above the lowlands (Figure 8e) look similar. Both profiles indicate a weak signature of the solar tide (mostly at $7^{\circ} \mathrm{S}$ ) at $12-14 \mathrm{hr}$ since no influence of orography is expected above lowlands (Figure 8f). The increase of the meridional speed in absolute value (from the red line to the blue line) is caused by the general poleward increase of the mean meridional speed at the cloud top level.

Thus, we conclude that the horizontal flow at cloud top level in the equatorial region is perturbed at 13-14 $\mathrm{hr}$. The perturbation of both zonal and meridional wind components may be explained by the solar tide. This effect is better seen in lowland regions where the orographic deceleration effect is absent.

\subsection{Latitude-Longitude and Solar-Related Variations in Individual Orbits}

In the previous sections we considered latitude-longitude variations of the mean zonal and meridional winds and found a local time dependence of their speed. These effects are visible in the series of images taken in individual orbits. It should be noted that in this case we see a combination of at least three processes: 

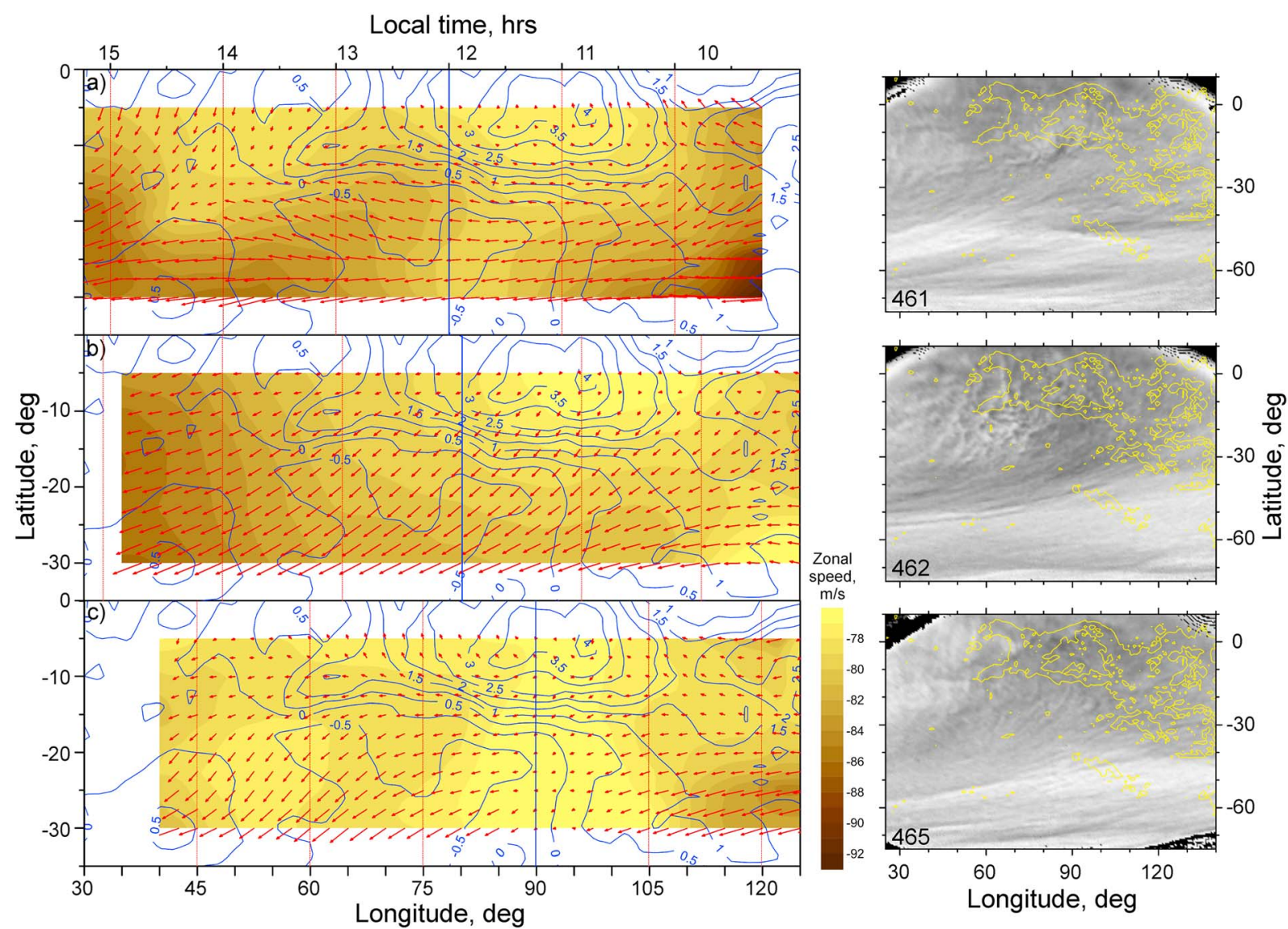

Figure 9. Wind fields for orbits \#0461 (a), \#0462 (b), and \#0465 (c; Tables S12-S14). The results were averaged over [15² E, $\left.10^{\circ} \mathrm{S}\right]$ bins (longitude, latitude) with a shift of $2.5^{\circ}$ in longitude and latitude. Variations of the zonal speed are shown in color. The vectors show the flow direction in a "superrotating" frame. They represent wind velocity after subtraction of the mean zonal speed $u_{0} \cdot \cos (\varphi)$ where $u_{0}=-75 \mathrm{~m} / \mathrm{s}$ and $\varphi$ is latitude. The surface topography is shown as blue contours. Vertical blue lines mark noon. Corresponding UV images in Cartesian projection are shown in the right column.

solar tide, mountain wave, and "Y" or "V" feature (resulting from the interaction of a Kelvin wave with the zonal flow: see, e.g., Titov et al., 2012; Peralta et al., 2015). The $Y$ feature is characterized by strong poleward deflections of the zonal flow (Patsaeva et al., 2015) that make the detection of the solar tide and mountain wave above Aphrodite Terra more difficult.

Orbit \#0461 (Figure 9a) shows a weak poleward deflection, in which case the zonal flow is less perturbed thus providing better conditions for observing the influence of topography and solar tide due to absence of the Y-feature. The weak poleward component of the flow makes clearly visible the motions of the zonal flow approximately following topographic contours of Aphrodite Terra. In this orbit the region of slow zonal wind is observed at $11-12 \mathrm{hr}$ above Ovda Regio $\left(85-95^{\circ} \mathrm{E}\right)$ and at $13-14 \mathrm{hr}$ in accordance with the tide observed (see Figure 8). In orbit \#0462 (Figure 9b) the circulation has a strong meridional component that masks the influence of surface topography and solar tide. The mountain wave is revealed as a local minimum (modulus) zonal speed above Ovda Regio. Orbit \#0462 shows the influence of the front of the Y-feature on the zonal flow. It is clearly visible at the center of image \#0462. In orbit \#0465 (Figure 9c) noon coincides with the area of maximum elevation in Aphrodite Terra. The Y-feature is visible only in the western part of the image. The clearly visible area of slow zonal wind is localized above Ovda Regio and extends from the equator to at least $30^{\circ} \mathrm{S}$.

\section{Discussion}

\subsection{Zonal Wind Above Aphrodite Terra}

Bertaux et al. (2016) found that the longitude profile of the mean zonal wind speed in the latitude band $10 \pm$ $5^{\circ} \mathrm{S}$ is correlated with the surface topography suggesting that the area of decelerated wind is shifted by $\sim 30^{\circ}$ 
downstream of Aphrodite Terra. Our results for the same latitude band are generally consistent with those of Bertaux et al. (2016). The digital data used in this paper have broader and more uniform local solar time coverage that allows us to study diurnal trends. In this work we investigated only the part of the zonal wind profile that contains Aphrodite Terra. Although the bulk wind profile is shifted downstream of the Aphrodite highlands (Figure 2a), the minimum velocity is reached above the highest point in Ovda Regio close to noon (Figures 3 and 5). In the afternoon the area of slow wind gradually moves downstream of Aphrodite Terra as local time increases (Figures 1 and 3). Figure 5 shows how the area of slow wind propagates to the south. Thus, the influence of the highest part of Aphrodite Terra manifests itself with the existence of a slow wind region in the latitude band $0-30^{\circ} \mathrm{S}$.

The deceleration of the zonal wind attached to Aphrodite Terra in the latitude band $10 \pm 5^{\circ} \mathrm{S}$ is seen for all daylight local times between 09 and $16 \mathrm{hr}$ LT (Figure 8a redline), but the deceleration is modulated by the position of the sun over Aphrodite Terra, being maximum at noon. In the frame of the gravity wave suggestion of Bertaux et al. (2016), this means that the pattern of gravity waves that affects the zonal circulation at high altitudes is changing with local time. This is facilitated by the very slow rotation of Venus: the Sun is moving in the sky by only $\sim 3^{\circ}$ per terrestrial day, as seen from the surface of Venus.

Horinouchi et al. (2018) analyzed the wind field derived from the Akatsuki Ultraviolet Imager (UVI) images acquired from December 2015 to March 2017. They reported a strong deceleration of the zonal wind around noon, suggesting a significant influence of the solar tide on the cloud top circulation, but, contrary to Bertaux et al. (2016), found very weak correlation with topography. There could be two possible explanations of the apparent disagreement. First, as also mentioned by Horinouchi et al. (2018), longitudinal coverage of UVI/Akatsuki observations is rather limited and does not allow a thorough investigation of the longitudinal dependence and its separation from the solar-related trend. Second, UVI/Akatsuki observations were carried out after the VEx mission had been completed and could miss the topography-related features if they are not persistent. We believe that further extensions of the Akatsuki observations as well as joint VMC/VEx and UVI/Akatsuki data analysis would help to resolve the discrepancy in future.

Figure 1 plotted for various local times (LTs) shows a westward shift of the wind minimum region. For instance, the wind minimum observed above Aphrodite Terra around $90^{\circ} \mathrm{E}$ to $10^{\circ} \mathrm{S}$ at $10-11 \mathrm{hr}$ LT moves westward by $15^{\circ}$ per $1 \mathrm{hr}$ to around $15^{\circ} \mathrm{E}$ at $15-16 \mathrm{~h} \mathrm{LT}$. At a given instant (absolute time), the local time decreases eastward by $1 \mathrm{hr}$ per $15^{\circ}$ longitude step. This means that the minimum of wind occurs at the same absolute time at all longitudes between $15^{\circ} \mathrm{E}$ and $90^{\circ} \mathrm{E}$. This corresponds to the same absolute time $\left(75^{\circ}\right.$ westward shift in $5 \mathrm{hr}$ ). This suggests that there is a non-migrating component in the thermal tide probably excited by the stronger solar heating above Aphrodite Terra.

We considered the variation of the cloud top altitude as a potential explanation for the lower wind speed above the highlands. In the near-IR spectral range the cloud top altitude at low latitudes is located at $70 \pm$ $2 \mathrm{~km}$ (see discussion in Khatuntsev et al., 2017, for details). Fedorova et al. (2016) found variations of the cloud top altitude of about $1 \mathrm{~km}$ depending on local time. The cloud top altitude in the UV spectral range is located at approximately the same altitude as in the near-IR (Cottini et al., 2012; Ignatiev et al., 2009). At noon we observe a deceleration of the mean zonal flow in the equatorial band above Aphrodite Terra $\left(7^{\circ} \mathrm{S}\right.$, red line in Figure $8 \mathrm{a}$ ) of about $12 \mathrm{~m} / \mathrm{s}$ compared to the areas above the lowlands $\left(7^{\circ} \mathrm{S}\right.$, red line in Figure 8d). Keeping in mind that the vertical wind shear is typically less than $2 \mathrm{~m} \cdot \mathrm{s}^{-1} \cdot \mathrm{km}^{-1}$ (Khatuntsev et al., 2017), the zonal speed variations with amplitude $12 \mathrm{~m} / \mathrm{s}$ would correspond to an altitude difference of $6 \mathrm{~km}$, which disagrees with the observed small variability of the cloud top altitude. Consequently, we interpret the observed change in the mean zonal flow velocity as real and not related to changes in the cloud top altitude.

\subsection{Vertical Propagation of Gravity Waves}

The wind field averaged within the local time bins is significantly slower above Aphrodite Terra at noon (Figure 1). In the afternoon the area of the slow wind displaces downstream and gradually fades out by 15- to 16-hr local time. As noted above, Bertaux et al. (2016) found a correlation of the zonal wind field derived from the VMC UV images with the surface topography. Kouyama et al. (2017) reported observations of the planetary bow-shaped feature by the LIR camera onboard Akatsuki in the thermal IR range. This signature is hemispherically symmetric and often appears in the afternoon above Aphrodite Terra, Thesis 
Regio, Atla Regio, and Beta Regio. Thus, several independent observations suggest a correlation of the cloud properties and wind field at the cloud top with the surface topography and local solar time.

The correlation with topography suggests the existence of a physical mechanism that provides a link between the surface and the cloud top. Following Lindzen (1981) and Young et al. (1987), Bertaux et al. (2016) argued that stationary gravity waves generated by Aphrodite Terra can propagate up to the bottom of the cloud deck $(\sim 50 \mathrm{~km})$ where they break transferring momentum to the mean flow and decelerating the zonal wind from this level to the cloud top. Propagation of gravity waves is possible only in a stable atmosphere. The Venus atmosphere is stable from the surface up to $\sim 50 \mathrm{~km}$, but an unstable layer was observed in the middle cloud layer (50-55 km) (Limaye et al., 2018; Tellmann et al., 2009). Thus, one has to look for or hypothesize mechanisms of gravity wave propagation through this region. Numerical simulations by the Venus GCM of Navarro et al. (2018) showed that the gravity waves generated by the diurnal cycle of the near surface atmospheric stability, which shows enhanced convection in the afternoon in the regions of topographic highs, can reach the cloud top and produce stationary bow-shaped features resembling those observed by LIR/Akatsuki (Fukuhara et al., 2017). However, Navarro et al. (2018) did not discuss mechanisms of wave propagation through the atmosphere and unstable region in particular.

The observed deceleration of the zonal flow and appearance of the planetary bow-shaped feature in the afternoon indicate that solar heating plays a significant role in both phenomena. Following Bertaux et al. (2016), we suggest that the zonal wind minima shown in Figure 2a result from a deceleration of the flow due to its interaction with the mountain waves generated by Aphrodite Terra. A strong heating of the upper cloud at noon due to the presence of the unknown UV absorber (Ekonomov et al., 1984) might stabilize the middle cloud below $\sim 58 \mathrm{~km}$ thus facilitating upward propagation of the waves. This suggestion is supported by Figure $8 \mathrm{a}$, showing that the deceleration over the mountains is maximum at noon, and quite symmetric with respect to noon. Indeed, the smaller is the solar zenith angle, the deeper the solar heating penetrates into the clouds. The possible increase of thermal static stability at the cloud top could favor gravity wave breaking. Vertical wavelengths of the gravity waves should decrease and their amplitude should increase with altitude, leading to strong local temperature gradients and creating conditions for the occurrence of static instabilities and gravity wave breaking (Hauchecorne et al., 1987). Gravity waves propagate upward without dissipation of energy until they reach the layer where the condition of instability, either static (negative potential temperature gradient) or dynamic (Richardson number $<0.25$ ), is fulfilled. Here they break and transfer momentum to the mean flow. However, it is quite unlikely that a stationary orographic (mountain) wave can propagate from the surface to the upper cloud layer without interaction with the mean flow and thus break at this level. Equation (10) in Hauchecorne et al. (1987) relates the vertical wavenumber $k_{z}$ to the intrinsic horizontal phase speed:

$$
k_{z}=\frac{N}{U-c},
$$

where $U$ is the mean wind, $c$ the horizontal phase speed, and $N$ the Brunt-Väisäilä frequency. Such a wave will have a very large vertical wavelength inducing small gradients of wind and temperature due to the fast mean wind $\left(\lambda_{z} \approx 31 \mathrm{~km}\right.$ with $U \approx 100 \mathrm{~m} / \mathrm{s}$ and $\left.N \approx 0.02 \mathrm{~s}^{-1}\right)$. Furthermore, the amplitude of this wave will grow exponentially due to the exponential decrease of the atmospheric density (energy conservation) and it is very probable that it will break before reaching the upper cloud layer. The density decreases by a factor of $\sim 1,000$ between the surface and $70 \mathrm{~km}$ and the wave amplitude increases inversely with the square root of the density. We propose another explanation invoking a mechanism that plays an important role in the Earth's mesosphere as described in detail in Becker and Vadas (2018). Orographic gravity waves propagate upward and break at different levels in the atmosphere as they reach an instability condition. The intermittency of such waves creates secondary gravity waves with a large spectrum of horizontal phase speeds. A part of these waves will propagate upwards with phase speeds much closer to the zonal wind speed at the level of upper clouds, leading to small vertical wavelengths and consequently large vertical wind and temperature gradients, and a high probability to reach a condition of instability and break. Application of this mechanism to the propagation of gravity waves from the surface to the cloud level on Venus is an important subject for future studies.

The above description is supported by a recent reanalysis of some radio occultations from both VEx and Akatsuki with a refined radio holographic method, yielding a better vertical resolution of temperature 
profiles (Imamura et al., 2018). According to these authors, “observed fine structures are manifestations of gravity waves ... [producing] thin turbulent layers ubiquitously above $\sim 60 \mathrm{~km} .$. [which] should induce mixing of atmospheric constituents, momentum, and energy, influencing the large-scale atmospheric structure." Clearly, when those turbulent layers result from the breaking of stationary gravity waves, the momentum mixing is the driving mechanism to decelerate the zonal flow.

The analysis of the VMC-derived wind field suggests a zonal flow deceleration from about noon to early afternoon (11- to 14-hr local time) above and downstream of Aphrodite Terra (Figure 8a). The observations by the LIR camera on Akatsuki showed a bow-shaped stationary wave from the afternoon to early evening (Kouyama et al., 2017). The LIR/Akatsuki camera mapped the emission from the entire strata of upper cloud with an effective altitude of $65 \mathrm{~km}$, while the UV channel of the VMC camera on VEx imaged the cloud top $(70-72 \mathrm{~km})$. The altitude difference between these observations is about $5-7 \mathrm{~km}$, which is comparable to the atmospheric scale height. Venera- 15 observations showed that the noon temperature peak at $35^{\circ} \mathrm{N}$ shifts in the direction of superrotation as altitude decreases (see Figure 7 in Zasova et al., 2007). Therefore, the lag between the zonal wind deceleration and occurrence of the stationary wave can be qualitatively explained by the difference in effective altitudes probed in the UV and thermal IR range.

Although spatial and temporal correlations between the observed deceleration of zonal wind and the bowshaped feature indicate a possible physical connection between these phenomena, the processes involved are still unclear and require further investigation.

\section{Conclusion}

In this paper we continued and detailed the analysis of the cloud top zonal wind deceleration first discovered by Bertaux et al. (2016). From tracking of the cloud features in the VMC/VEx UV images we found that the zonal wind at the cloud top is decelerated by $13.4 \pm 4.4 \mathrm{~m} / \mathrm{s}$ above Aphrodite Terra, a vast highland in the equatorial region. This value is statistically significant since the typical standard error of the mean is 1-2 $\mathrm{m} / \mathrm{s}$. The meridional wind component is also affected by the surface topography. We also found that the influence of topography on the cloud top winds depends on local solar time. The most pronounced deceleration of the zonal wind is observed at noon above Ovda Regio, the highest province of Aphrodite Terra. Later in the afternoon the area of slow wind moves downstream and fades out by the evening. The amplitude of the wind deceleration decreases and shifts downstream as we move south from Aphrodite Terra. We tentatively attributed the observed wind deceleration to interaction of the gravity (mountain) waves generated by Aphrodite Terra with the atmospheric circulation. A perturbation of both zonal and meridional wind components was observed in the equatorial region around 13-14 $\mathrm{hr}$ and may be explained by a solar tide. Although the mechanism presented in this paper is in qualitative agreement with other observations and models, we realize that further investigations are needed. Analysis of wind fields observed by Akatsuki would be especially useful to unveil details of this phenomenon.

\section{Appendix A: "Slow" and "Fast" Wind Subsets}

In order to verify that the trends in the geographical distribution of the zonal wind observed in Figure 1 were not due to a possible bias induced by a particular sampling of the data set, we conducted a dichotomy exercise, separating the data set into two subsets, one called the "slow" wind subset and the other the "fast" wind subset. This is a classic method for testing the robustness of certain results in a data set: the same results should be obtained if you separate the primary data into two subsets on a somewhat arbitrary criterion.

Figure 1 was established with the data sets listed in the Table 1 of the manuscript. For each data set from the table we calculated an average zonal velocity in the latitude belt $0-40^{\circ} \mathrm{S}$. Individual wind vectors were split into two subsets: the fast subset with velocities exceeding the average one (in modulus), and the slow subset with velocities less than the average value. The average value was changing during the Venus Express mission due to the increase of the zonal speed (Khatuntsev et al., 2013). Applying the same processing to all data sets from table 1 resulted in two (slow and fast) subsets of wind vectors, and the maps shown in Figures A1 (left) and A1(right) correspond respectively to the slow and fast subsets. Both figures display similar trends: at about noon there is a slow wind area located above and slightly downstream of Aphrodite Terra highlands (60-150 ${ }^{\circ}$ E longitude), and this slow wind area moves downstream as local time progresses from 10-11 to 15$16 \mathrm{hr}$. 

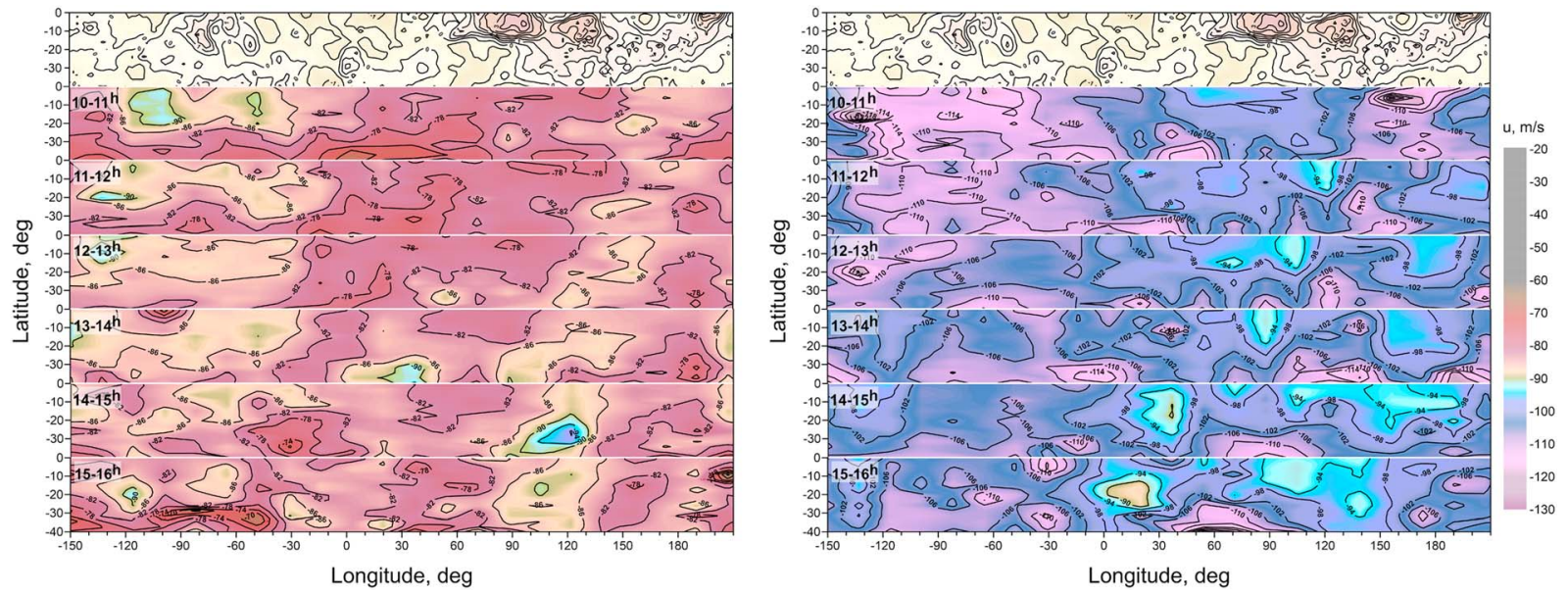

Figure A1. Spatial distribution of the average zonal wind speed at the cloud top plotted for 1-hr local time intervals. In this map, only wind vectors slower (in modulus) than the average (computed for one observation data set) are kept ("slow" wind subset). The local time is the same for all points in the wind maps; it is indicated in the upper left corner of each panel. Therefore, these "maps" are not actual, instantaneous maps of the wind field. Topographic maps from the National Aeronautics and Space Administration Magellan mission are presented in the upper panel with altitude isocontours. For other maps, the velocity of the zonal wind is both color coded and represented with isovelocity contours (left); the same for the "fast" wind subset (right). The zonal velocity color coding is the same for (left) and (right).

\section{Acknowledgments}

J. -L. Bertaux and M. V. Patsaeva were supported by the Ministry of Science and Higher Education of the Russian Federation Grant 14.W03.31.0017. I. V. Khatuntsev and L. V. Zasova would like to thank the program AAAA-A18118052890092-7 of the Ministry of Science and Higher Education of the Russian Federation for the support. The authors are grateful to the ESA Venus Express mission and science operation teams and colleagues at MPS and DLR for flawless operations of the Venus Monitoring Camera. We thank A. A. Fedorova and N. I. Ignatiev for useful discussion. We thank the anonymous reviewers for their useful comments that helped improve the manuscript. The data used are listed in the references, tables, and figures. Original Venus Monitoring Camera data used in this work are available at the ESA Planetary Science Archive (PSA; ftp:// psa.esac.esa.int/pub/mirror/VENUSEXPRESS/VMC/).
Therefore, this dichotomy exercise provides convincing evidence that the correlation of the wind field with topography and its local time trend are persistent features of the circulation and not artifacts related to the data selection.

\section{References}

Altieri, F., Migliorini, A., Zasova, L., Shakun, A., Piccioni, G., \& Bellucci, G. (2014). Modeling VIRTIS/VEX O ${ }_{2}\left(\mathrm{a}^{1} \Delta_{\mathrm{g}}\right)$ nightglow profiles affected by the propagation of gravity waves in the Venus upper mesosphere. Journal of Geophysical Research: Planets, 119, 2300-2316. https://doi.org/10.1002/2013JE004585

Becker, E., \& Vadas, S. L. (2018). Secondary gravity waves in the winter mesosphere: results from a high-resolution global circulation model. Journal of Geophysical Research: Atmospheres, 123, 2605-2627. https://doi.org/10.1002/2017JD027460

Bertaux, J.-L., Khatuntsev, I. V., Hauchecorne, A., Markiewicz, W. J., Marcq, E., Lebonnois, S., et al. (2016). Influence of Venus topography on the zonal wind and UV albedo at cloud top level: The role of stationary gravity waves. Journal of Geophysical Research: Planets, 121, 1087-1101. https://doi.org/10.1002/2015JE004958

Cottini, V., Ignatiev, N. I., Piccioni, G., Drossart, P., Grassi, D., \& Markiewicz, W. J. (2012). Water vapor near the cloud tops of Venus from Venus Express/VIRTIS dayside data. Icarus, 217(2), 561-569. https://doi.org/10.1016/j.icarus.2011.06.018

Del Genio, A. D., \& Rossow, W. B. (1990). Planetary scale waves and the cyclic nature of cloud top dynamics on Venus. Journal of the Atmospheric Sciences, 47(3), 293-318. https://doi.org/10.1175/1520-0469(1990)047<0293:PSWATC >2.0.CO;2

Drossart, P., Piccioni, G., Adriani, A., Angrilli, F., Arnold, G., Baines, K. H., et al. (2007). Scientific goals for the observation of Venus by VIRTIS on ESA/Venus express mission. Planetary and Space Science, 55(12), 1653-1672. https://doi.org/10.1016/j.pss.2007.01.003

Ekonomov, A. P., Moroz, V. I., Moshkin, B. E., Gnedykh, V. I., Golovin, Y. M., \& Grigoriev, A. V. (1984). Scattered UV solar radiation within the clouds of Venus. Nature, 307(5949), 345-347. https://doi.org/10.1038/307345a0

Fedorova, A., Marcq, E., Luginin, M., Korablev, O., Bertaux, J. L., \& Montmessin, F. (2016). Variations of water vapor and cloud top altitude in the Venus' mesosphere from SPICAV/VEx observations. Icarus, 275, 143-162. https://doi.org/10.1016/j.icarus.2016.04.010

Fukuhara, T., Futaguchi, M., Hashimoto, G. L., Horinouchi, T., Imamura, T., Iwagaimi, N., et al. (2017). Large stationary gravity wave in the atmosphere of Venus. Nature Geoscience, 10(2), 85-88. https://doi.org/10.1038/ngeo2873

Gorinov, D. A., Khatuntsev, I. V., Zasova, L. V., Turin, A. V., \& Piccioni, G. (2018). Circulation of Venusian atmosphere at 90-110 km based on apparent motions of the $\mathrm{O}_{2} 1.27 \mu \mathrm{m}$ nightglow from VIRTIS-M (Venus Express) data. Geophysical Research Letters, 45, $2554-2562$. https://doi.org/10.1002/2017GL076380

Hauchecorne, A., Chanin, M. L., \& Wilson, R. (1987). Mesospheric temperature inversion and gravity wave breaking. Geophysical Research Letters, 14(9), 933-936. https://doi.org/10.1029/GL014i009p00933

Horinouchi, T., Kouyama, T., Lee, Y. J., Murakami, S., Ogohara, K., Takagi, M., et al. (2018). Mean winds at the cloud top of Venus obtained from two-wavelength UV imaging by Akatsuki. Earth, Planets and Space, 70(1). https://doi.org/10.1186/s40623-017-0775-3

Ignatiev, N. I., Titov, D. V., Piccioni, G., Drossart, P., Markiewicz, W. J., Cottini, V., et al. (2009). Altimetry of the Venus cloud tops from the Venus Express observations. Journal of Geophysical Research, 114, E00B43. https://doi.org/10.1029/2008JE003320

Imamura, T., Miyamoto, M., Ando, H., Häusler, B., Pätzold, M., Tellmann, S., et al. (2018). Fine vertical structures at the cloud heights of Venus revealed by radio holographic analysis of Venus Express and Akatsuki radio occultation data. Journal of Geophysical Research: Planets, 123, 2151-2161. https://doi.org/10.1029/2018JE005627

Khatuntsev, I. V., Patsaeva, M. V., Titov, D. V., Ignatiev, N. I., Turin, A. V., Fedorova, A. A., \& Markiewicz, W. J. (2017). Winds in the middle cloud deck from the near-IR imaging by the Venus Monitoring Camera onboard Venus Express. Journal of Geophysical Research: Planets, 122, 2312-2327. https://doi.org/10.1002/2017JE005355 
Khatuntsev, I. V., Patsaeva, M. V., Titov, D. V., Ignatiev, N. I., Turin, A. V., Limaye, S. S., et al. (2013). Cloud level winds from the Venus Express Monitoring Camera imaging. Icarus, 226(1), 140-158. https://doi.org/10.1016/j.icarus.2013.05.018

Kouyama, T., Imamura, T., Nakamura, M., Satoh, T., \& Futaana, Y. (2013). Long-term variation in the cloud-tracked zonal velocities at the cloud top of Venus deduced from Venus Express VMC images. Journal of Geophysical Research: Planets, 118, 37-46. https://doi.org/ 10.1029/2011JE004013

Kouyama, T., Imamura, T., Taguchi, M., Fukuhara, T., Sato, T. M., Yamazaki, A., et al. (2017). Topographical and local time dependence of large stationary gravity waves observed at the cloud top of Venus. Geophysical Research Letters, 44, 12,098-12,105. https://doi.org/ 10.1002/2017GL075792

Limaye, S. S., Grassi, D., Mahieux, A., Migliorini, A., Tellmann, S., \& Titov, D. (2018). Venus Atmospheric Thermal Structure and Radiative Balance. Space Science Reviews, 214(5). https://doi.org/10.1007/s11214-018-0525-2

Lindzen, R. S. (1981). Turbulence and stress owing to gravity wave and tidal breakdown. Journal of Geophysical Research, 86(C10), 9707-9714. https://doi.org/10.1029/JC086iC10p09707

Markiewicz, W. J., Titov, D. V., Ignatiev, N., Keller, H. U., Crisp, D., Limaye, S. S., et al. (2007). Venus Monitoring Camera for Venus Express. Planetary and Space Science, 55(12), 1701-1711. https://doi.org/10.1016/j.pss.2007.01.004

Moissl, R., Khatuntsev, I., Limaye, S. S., Titov, D. V., Markiewicz, W. J., Ignatiev, N. I., et al. (2009). Cloud top winds from tracking UV features in Venus Monitoring Camera images. Journal of Geophysical Research, 114, E00B31. https://doi.org/10.1029/2008JE003117

Navarro, T., Schubert, G., \& Lebonnois, S. (2018). Atmospheric mountain wave generation on Venus and its influence on the solid planet's rotation rate. Nature Geoscience, 11(7), 487-491. https://doi.org/10.1038/s41561-018-0157-x

Patsaeva, M. V., Khatuntsev, I. V., Patsaev, D. V., Titov, D. V., Ignatiev, N. I., Markiewicz, W. J., \& Rodin, A. V. (2015). The relationship between mesoscale circulation and cloud morphology at the upper cloud level of Venus from VMC/Venus Express. Planetary and Space Science, 113-114(08), 100-108. https://doi.org/10.1016/j.pss.2015.01.013

Peralta, J., Hueso, R., Sánchez-Lavega, A., Lee, Y. J., García-Muñoz, A., Kouyama, T., et al. (2017). Stationary waves and slowly moving features in the night upper clouds of Venus. Nature Astronomy, 1(8). https://doi.org/10.1038/s41550-017-0187

Peralta, J., Sánchez-Lavega, A., López-Valverde, M. A., Luz, D., \& Machado, P. (2015). Venus's major cloud feature as an equatorially trapped wave distorted by the wind. Geophysical Research Letters, 42, 705-711. https://doi.org/10.1002/2014GL062280

Picciali, A., Titov, D. V., Sanchez-Lavega, A., Peralta, J., Shalygina, O., Markiewicz, W. J., \& Svedhem, H. (2014). High latitude gravity waves at the Venus cloud tops as observed by the Venus Monitoring Camera on board Venus Express. Icarus, 227, 94-111. https://doi. org/10.1016/j.icarus.2013.09.012

Svedhem, H., Titov, D. V., Taylor, F. W., \& Witasse, O. (2009). The Venus Express mission. Journal of Geophysical Research, 114, E00B33. https://doi.org/10.1029/2008JE003290

Takagi, M., Sugimoto, N., Ando, H., \& Matsuda, Y. (2018). Three-dimensional structures of thermal tides simulated by a Venus GCM. Journal of Geophysical Research: Planets, 123, 335-352. https://doi.org/10.1002/2017JE005449

Tellmann, S., Pätzold, M., Häusler, B., Bird, M. K., \& Tyler, G. L. (2009). Structure of the Venus neutral atmosphere as observed by the Radio Science experiment VeRa on Venus Express. Journal of Geophysical Research, 114, E00B36. https://doi.org/10.1029/2008JE003204

Titov, D. V., Markiewicz, W. J., Ignatiev, N. I., Song, L., Limaye, S. S., Sánchez-Lavega, A., et al. (2012). Morphology of the cloud tops as observed by the Venus Express Monitoring Camera. Icarus, 217(2), 682-701. https://doi.org/10.1016/j.icarus.2011.06.020

Titov, D. V., Svedhem, H., Koschny, D., Hoofs, R., Barabash, S., Bertaux, J., et al. (2006). Venus Express science planning. Planetary and Space Science, 54(13-14), 1279-1297. https://doi.org/10.1016/j.pss.2006.04.017

Young, R. E., Walterscheid, R. L., Schubert, G., Seiff, A., Linkin, V. M., \& Lipatov, A. N. (1987). Characteristics of gravity waves generated by surface topography on Venus: Comparison with the VEGA balloon results. Journal of the Atmospheric Sciences, 44(18), 2628-2639. https://doi.org/10.1175/1520-0469(1987)044\%3C2628:COGWGB\%3E2.0.CO;2

Zasova, L. V., Ignatiev, N. I., Khatuntsev, I. V., \& Linkin, V. M. (2007). Structure of the Venus atmosphere. Planetary and Space Science, 55(12), 1712-1728. https://doi.org/10.1016/j.pss.2007.01.011

Zasova, L. V., Khatountsev, I. V., Ignatiev, N. I., \& Moroz, V. I. (2002). Local time variations of the middle atmosphere of Venus: Solarrelated structures. Advances in Space Research, 299(2), 243-248. https://doi.org/10.1016/S0273-1177(01)00574-9

Zasova, L.V., Khatuntsev, I.V., Patsaeva M.V., Ignatiev, N. I, Rodin A.V., Turin A.V. (2015). Reflection of surface topography in Venus atmosphere, Moscow Solar System Symposium (pp. 103-105.http://ms2015.cosmos.ru/sites/ms2015.cosmos.ru/files/6m-s3_abstract_ book.pdf

Zasova, L. V., Linkin, V. M., \& Khatuntsev, I. V. (2000). Zonal wind in the middle atmosphere of Venus. Cosmic Research, $38,49-65$. 